\title{
Experimental Study and Failure Mechanism Analysis of Rubber Fiber Concrete under the Compression-Shear Combined Action
}

\author{
Juntao Zhang, ${ }^{1}$ Zhenpeng Yu, ${ }^{2}$ Xinjian Sun ${ }^{1},{ }^{3}$ Guangli Zhang, ${ }^{4}$ and Wenguo Pan ${ }^{5}$ \\ ${ }^{1}$ Yellow River Engineering Consulting Co., Ltd., Zhengzhou 450003, China \\ ${ }^{2}$ Department of Civil Engineering, School of Mechanics and Engineering Science, Shanghai University, Shanghai 200444, China \\ ${ }^{3}$ Qinghai University, Xining 810016, China \\ ${ }^{4}$ Nalengelehe Water Conservancy Project Construction Management Bureau, Geermu 816000, China \\ ${ }^{5}$ Sinohydro Foundation Engineering Co., Ltd., Tianjin 301700, China \\ Correspondence should be addressed to Xinjian Sun; sunxj@qhu.edu.cn
}

Received 24 February 2021; Revised 26 April 2021; Accepted 24 June 2021; Published 7 July 2021

Academic Editor: Shazim A. Memon

Copyright ( 2021 Juntao Zhang et al. This is an open access article distributed under the Creative Commons Attribution License, which permits unrestricted use, distribution, and reproduction in any medium, provided the original work is properly cited.

\begin{abstract}
In order to examine the compression-shear combined mechanical properties of rubber fiber concrete, an experimental study was carried out on rubber fiber concrete of three different configurations using a material compression-shear testing machine by considering different axial compression ratios. The failure modes and shear stress-strain curves of rubber fiber concrete under different loading conditions were obtained. By comparatively analyzing the mechanical parameters of rubber fiber concrete under different axial compression ratios, the following conclusions were drawn. With the increase of the axial compression ratio, the failure mode in the shear direction gradually developed from a relatively straight crack to a main crack accompanied by a certain amount of axial cracks; meanwhile, the number of concrete slags on the shear failure section was gradually increased and the friction marks were gradually deepened. The addition of rubber particles increased the randomness and discreteness of the concrete upon failure, while fibers inhibited the development of oblique micro-cracks and the dropping of concrete slags. The shear stress of the concrete specimen containing rubber particles was significantly lower than those without rubber particles. Comparatively, fibers showed little effect on the shear stress. As the axial compression ratio increased, the shear stress and shear strain of rubber fiber concrete were gradually increased, but the increasing amplitude of shear stress tended to become flattened. Under the influence of the axial compression ratio, the shear stress of C- $0 \%-0 \%, \mathrm{C}-30 \%-0 \%$, and C-30\%- $0.6 \%$ was increased by 4.57 times, 3.26 times, and 2.69 times, respectively, suggesting a gradually decreasing trend. At the same time, based on the principal stress space and the octahedral stress space, the compression-shear combined failure criterion was proposed for the three different rubber fiber concretes. The research findings are of great significance to the engineering application and development of rubber fiber concrete.
\end{abstract}

\section{Introduction}

Rubber fiber concrete is a relatively new type of concrete that is formed by incorporating rubber particles and fibers into the concrete mixture. By organically combining the advantages of rubber concrete and fiber concrete, the performance of rubber fiber concrete is obviously improved $[1,2]$. Moreover, as the rubber particles are generally sourced from waste tires, the manufacturing process of rubber fiber concrete can achieve secondary utilization of waste tires so as to avoid the impact of waste tires on environmental safety. In view of this, rubber fiber concrete has a high research value and a promising engineering application prospect [3].

At present, the research on rubber concrete and polypropylene fiber concrete mainly concentrates on the aspects of mix proportion design, mechanical properties, and durability. Among the studies on the mechanical properties of rubber concrete, $\mathrm{Lv}$ et al. [4] examined the mechanical properties of rubber concrete by replacing part of fine aggregates with rubber powders at equal volume, and found that the strength of rubber concrete decreased at a high rate when the rubber powder content was less than $50 \%$ and 
decreased at a flattened rate when the rubber powder content was above 50\%. Aslani [5] studied the mechanical properties of rubber concrete with different particle sizes and concluded that the size of rubber particles had a significant effect on the compressive strength of rubber concrete and a larger particle size corresponded to a higher decreasing rate of concrete strength. By adding rubber particles into the concrete, Xie et al. [6] found that rubber particles could significantly improve the ductility of concrete. Fadhli [7] and Khaloo et al. [8] examined the influence of rubber particles on the development of concrete cracks and found that rubber particles had a certain inhibitory effect on the generation and development of cracks, which in turn improved the toughness of concrete. Atahan and Yücel [9] and Coventry et al. [10] carried out impact performance experiments on rubber concrete. Their results showed that rubber concrete had good impact resistance and was able to absorb a high amount of impact energy. For the studies on the mechanical properties of polypropylene fiber concrete, Nkem Ede et al. [11] examined the mechanical properties of concrete by considering different fiber contents. Their results showed that the concrete delivered the best performance when the fiber content was equal to $0.25 \%$ (the compressive strength was increased by about $9 \%$ and the bending resistance was increased by about 65\%). Bagherzadeh et al. [12] reported that $19 \mathrm{~mm}$ long polypropylene fiber had no significant effect on the compressive strength of concrete but could improve two toughness indicators of concrete, i.e., the splitting tensile strength and bending strength. The experimental study conducted by Arefi and Mollaahmadi [13] indicated that polypropylene coarse fibers could increase the bending strength of concrete. More specifically, the bending performance of concrete was gradually enhanced with the increase of fiber length; however, fine fibers had little effect on the bending resistance of concrete. Banthia and Gupta [14] studied the effect of polypropylene fiber geometry on the plastic shrinkage and cracking of concrete and found that finer fibers were more effective than thicker fibers, and longer fibers were more effective than shorter fibers. The short fibers that are added into concrete can act as a sort of mass reinforcing agent to provide crack control. This is mainly attributed to the fibers' capacity of tensile stress transfer across the cracking surfaces after failure (also known as crack-bridging) $[15,16]$. Thus, during the development of cracks, fibers can provide great resistance to shear, allowing FRC to demonstrate a pseudo-ductile response with improved energy dissipation ability and increased residual strength (particularly in tension) in comparison with the brittleness behavior of ordinary concrete [17]. The present study also indicated that fibers had a significant impact on the shear performance of the structural components of FRC. Because fibers can provide improved shear strength upon cracking failure, the overall response of the structural components is increased under cyclic (reversal) loading $[18,19]$. Ultimately, FRC shows better deformation ability, enhanced formation of cracks, larger residual stress, and improved energy dissipation ability in comparison with nonfibrous concrete [20]. The literature [21] applied four different methods to treat rubber particles, and the specimen treated by lime showed relatively better mechanical properties.

Studies focusing on the mechanical properties of rubber concrete and fiber concrete, as mentioned above, were all carried out using the uniaxial stress method. In actual engineering, concrete is more often subjected to multiaxial stress conditions rather than uniaxial stress conditions. Therefore, comprehensive investigations on the performance of concrete under multiaxial stress conditions are conducive for a better understanding of the mechanical properties of concrete, so as to rationally design the applications of concrete in engineering practice [22-31]. The research on multiaxial mechanical properties of concrete is generally implemented using the conventional tri-axial apparatus and true tri-axial apparatus. Comparatively, the true tri-axial apparatus is more consistent with the actual stress environment. To date, a large volume of literature has addressed the multiaxial mechanical properties of ordinary concrete, mainly from the perspectives of multiaxial stress mode, loading path, and loading environment [26, 27]. However, the shear mechanical properties of concrete are often neglected, especially the experimental study under compression-shear multiaxial loading. The literature [28] carried out an experimental study on the multiaxial mechanical properties of ordinary concrete by using the compression-shear testing machine and proposed the corresponding failure criterion. According to the literature review above, the shear multiaxial mechanical properties of concrete have been examined by several existing studies, but reports on the shear multiaxial mechanical properties of rubber concrete and rubber fiber concrete are rarely seen. In order to provide a solid theoretical basis for the engineering applications of rubber concrete and rubber fiber concrete, there is a great significance to initiate comprehensive studies on the shear multiaxial mechanical properties of rubber fiber concrete.

In this paper, the shear multiaxial stress mechanisms of ordinary concrete, rubber concrete, and rubber fiber concrete were explored and analyzed through an experimental study on the compression-shear multiaxial mechanical properties of these three different types of concrete. Compared with the existing literature, the present study demonstrated a certain novelty in research objects and methods. The failure modes and shear stress-strain curves under different axial compression ratios were obtained, and the results were used to analyze the effects of rubber, fiber, and axial compression ratio on the mechanical parameters of concrete and to explain the stress mechanism from a microscopic perspective. Meanwhile, the compression-shear multiaxial failure criterion of rubber fiber concrete was proposed based on the principal stress space and octahedral stress space, respectively. The research findings are of great significance to the engineering application and development of rubber fiber concrete.

\section{Experiment Plan}

2.1. Specimen Design and Mix Proportion. This experimental study intended to examine the mechanical properties of 
three different types of rubber fiber concrete under the compression-shear combined environment. By referencing to the addition amounts of rubber particles and polypropylene fibers in the relevant literature [2, 29], three different concrete specimens were designed: (1) C- $0 \%-0 \%$ (the concrete without rubber particles and polypropylene fibers, i.e., ordinary concrete); (2) C-30\%-0\% (the concrete containing only $30 \%$ of rubber particles, i.e., rubber concrete); (3) C-30\%- $0.3 \%$ (the concrete containing $30 \%$ of rubber particles and $0.6 \%$ of polypropylene fiber, i.e., rubber fiber concrete). The designed strength of ordinary concrete was $30 \mathrm{MPa}$. The concrete mix proportions were determined in accordance with the "Specification for mix proportion design of ordinary concrete" (JGJ55-2011). The sources of water, cement (ordinary Portland cement P. O 42.5), fine aggregates (river sands, fineness modulus: 2.5, apparent density: $2650 \mathrm{~kg} / \mathrm{m}^{3}$, and bulk density: $\left.1850 \mathrm{~kg} / \mathrm{m}^{3}\right)$, and coarse aggregates (natural gravel, particle size: $4-16 \mathrm{~mm}$, apparent density: $2580 \mathrm{~kg} / \mathrm{m}^{3}$ ) used in all the three types of concrete were the same. The rubber particle replacement ratio was determined based on the principle of equalvolume replacement of fine aggregates with rubber particles. The specific mix proportions of the three different types of concrete are shown in Table 1.

The rubber particle size ranged from 2to $5 \mathrm{~mm}$, with an apparent density of $1270 \mathrm{~kg} / \mathrm{m}^{3}$, a bulk density of $820 \mathrm{~kg} / \mathrm{m}^{3}$, a fiber content of $\leq 0.1 \%$, a tensile strength of $\geq 15 \mathrm{MPa}$, and an elongation at break of $\geq 500 \%$. The physical properties of polypropylene fibers were provided by the manufacturer as follows: diameter $0.1 \mathrm{~mm}$, length $19 \mathrm{~mm}$, tensile strength $322 \mathrm{MPa}$, elastic modulus $4.9 \mathrm{GPa}$, and density $0.91 \mathrm{~g} / \mathrm{cm}^{3}$. The samples of rubber particles and polypropylene fibers used in this study are shown in Figure 1.

The test specimens of rubber fiber concrete were prepared in the following steps: (1) add weighed cement, fine aggregates, and rubber particles into the mixer for thorough mixing; (2) add fibers into the mixture for further mixing; (3) add weighed water into the mixture and stir the mixture thoroughly until reaching a uniform viscous state; (4) pour the mixture into the test mold and place the mold on a vibrating table to vibrate compactly; (5) release the mold after 1 day and place the specimen into a standard curing room for 28 days before carrying out the designed test.

2.2. Loading Plan and Equipment. In order to examine the mechanical properties of rubber fiber concrete under the compression-shear combined condition, two different loading methods were configured: uniaxial compression and compression-shear combined stress. More specifically, the compression-shear combined working conditions consist of five different axial compression ratios $(\xi): 0 \%$ $f_{c} A_{s}, 13.8 \% f_{c} A_{s}, 20.7 \% f_{c} A_{s}, 27.6 \% f_{c} A_{s}$ and $41.4 \% f_{c} A_{s}$ (where $f_{c}$ is the uniaxial compressive strength of rubber fiber concrete, unit: $\mathrm{MPa} ; A_{s}$ is the area of the shear failure section, unit: $\mathrm{mm}^{2}$ ). Due to the randomness and discreteness of concrete materials, three specimens were prepared for each working condition, and the mean value was calculated for analysis.
By referencing to the requirements on specimen size and equipment limitations in the relevant literature, the specimen size was designed to be $100 \mathrm{~mm} \times 100 \mathrm{~mm} \times 100 \mathrm{~mm}$ for both uniaxial compression and compression-shear tests in this study. The uniaxial compression was loaded by a hydraulic servo, which is equipped with load sensors and displacement sensors. The maximum range of the axial load sensor on the hydraulic servo machine is 100 tons, and the maximum displacement is $\pm 70 \mathrm{~mm}$. The maximum deviation of the load sensor is $0.1 \%$ of its maximum measurement range. The maximum deviation of the displacement sensor is $\pm 0.00005 \mathrm{~mm}$. Both sensors satisfy the experiment requirements. The uniaxial compression test was implemented by the displacement-controlled loading method at a loading rate of $0.6 \mathrm{~mm} / \mathrm{min}$. Loading would be terminated once the testing specimen failed. For the compression test of rubber fiber concrete, only the compressive strength parameters were obtained.

The compression-shear test was implemented using a material compression-shear testing machine. Different from other shear testing methods, this equipment applies the direct shear method to obtain the shear load of the concrete. In this way, the impact of bending effect, rotation effect, and friction effect on the test results can be effectively controlled [28]. The material compression-shear testing machine is equipped with independent load sensors and displacement sensors in both the axial and transverse directions. The maximum range of the axial load sensor is 100 tons, and the maximum displacement is $\pm 45 \mathrm{~mm}$. The maximum range of the transverse load sensor is 50 tons, and the maximum displacement is $\pm 45 \mathrm{~mm}$. The precision of the sensors is the same as that of the hydraulic servo, which can satisfy the experiment requirements. In this study, the compressionshear test was implemented by the constant lateral loading method, that is, the axial load was applied first at a loading rate of $0.5 \mathrm{MPa} / \mathrm{min}$, and when the axial load reached the specified axial compression ratio, the shear load would then be applied laterally using the displacement-controlled method at a loading rate of $0.6 \mathrm{~mm} / \mathrm{min}$, until failure [20]. Once the machine began to apply the shear load, the sensors would start collecting data. Figure 2 shows a schematic diagram of the compression-shear loading equipment and the loading process. During the compression-shear combined test of rubber fiber concrete, the shear load values, shear deformation values, and axial deformation values were obtained.

\section{Analysis of Experiment Results}

3.1. Failure Mode. While examining the mechanical properties of concrete under the compression-shear combined condition, analysis of shear failure mode can help to intuitively reveal the influence of the axial compression ratio and material characteristics on the shear mechanical properties of rubber fiber concrete. In this paper, the characteristics of rubber fiber concrete under the compression-shear combined stress were analyzed from the perspectives of axial compression ratio and material properties. In view of space limitation, typical working conditions were selected for 
TABLe 1: Mix proportions of rubber fiber concrete $\left(\mathrm{kg} / \mathrm{m}^{3}\right)$.

\begin{tabular}{lcccccc}
\hline Condition & Cement & Water & Fine aggregate & Rubber particles & Coarse aggregate & Polypropylene fiber \\
\hline C- $0 \%-0 \%$ & 279 & 178 & 780 & 0 & 1034 & 0 \\
C-30\%-0\% & 279 & 178 & 546 & 96.9 & 1034 & 0 \\
C-30\%-0.6\% & 279 & 178 & 546 & 96.9 & 1034 & 12.80 \\
\hline
\end{tabular}

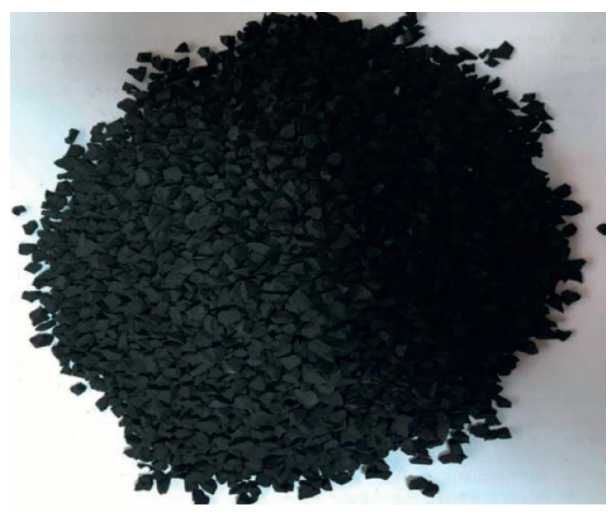

(a)

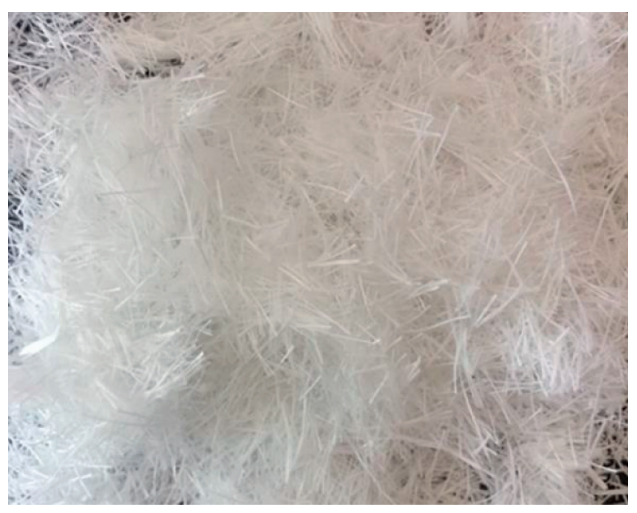

(b)

FIgURE 1: Rubber particles and polypropylene fibers. (a) Rubber particles. (b) Polypropylene fibers.

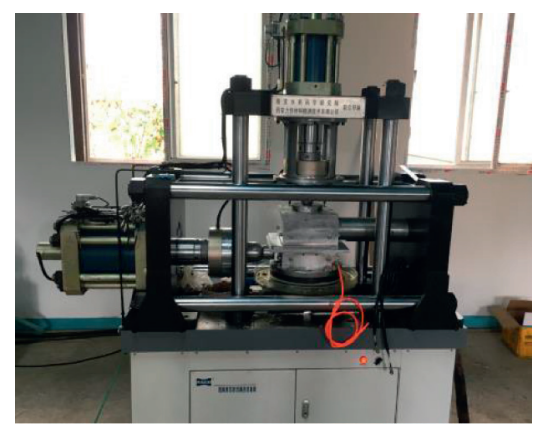

(a)

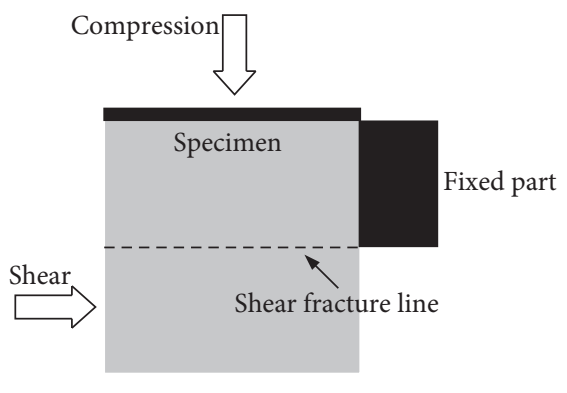

(b)

FIgURE 2: (a) Loading equipment and (b) loading schematic diagram.

common failure modes to study the mechanical properties of rubber fiber concrete from a macroscopic perspective.

3.1.1. Influence of Axial Compression Ratio. To examine the influence of different axial compression ratios on the shear failure mode of rubber fiber concrete, the C-30\%-0\% working condition was selected as the example for analyzing the effect of axial compression ratio on the failure mode in the shear direction, and C-30\%-0.6\% was selected as the example for analyzing the effect of axial compression ratio on the shear failure section, as shown in Figures 3 and 4, respectively.

As shown in Figure 3, when the axial compression ratio was $10 \% f_{c} A_{s}$, the rubber fiber concrete formed the main crack in the shear direction, which basically fluctuated along a straight line and penetrated the entire shear direction. When the axial compression ratio was increased to $20.7 \%$ $f_{c} A_{s}$, the rubber fiber concrete not only formed the main crack in the shear direction but also two oblique cracks with an angle of about $45^{\circ}$ from the main crack. The failure mode at $20.7 \% f_{c} A_{s}$ differed significantly from that at $0 \% f_{c} A_{s}$. This is mainly because, during the shear loading process, the specimen will form an oblique cracking failure mode under the axial compression. When the axial compression ratio was further increased to $41.4 \% f_{c} A_{s}$, the rubber fiber concrete not only formed a relatively straight main crack in the shear direction but also a certain amount of vertical cracks that are intersecting with the main crack, accompanied by dropping of a small amount of concrete blocks. The underlying mechanism behind this failure mode is that: when the axial compression is relatively low, the failure of concrete is mainly caused by the shear load (i.e., the failure mode of the specimen is basically irrelevant to the axial compression in this situation); when the axial compression is relatively high, the effect of axial load on the failure mode becomes apparent 


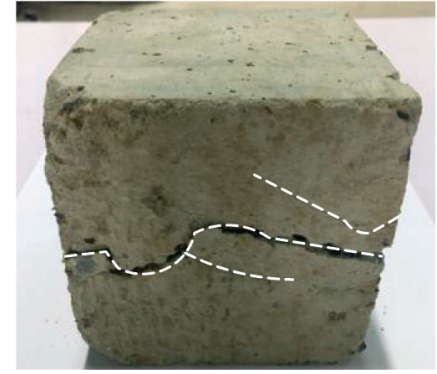

(a)

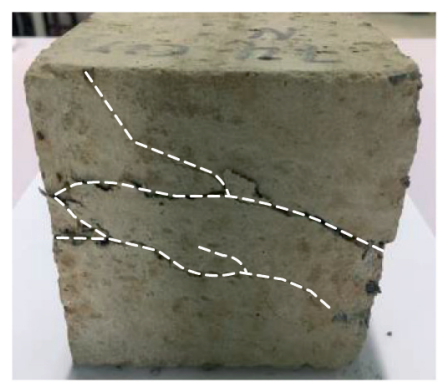

(b)

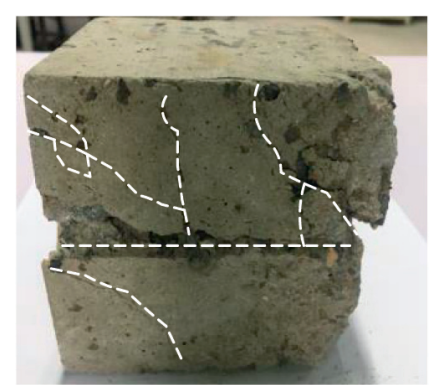

(c)

FIGURE 3: The influence of axial compression ratio on the shear failure mode of rubber fiber concrete. (a) $0 \% f_{c} A_{s}$. (b) $20.7 \% f_{c} A_{s}$. (c) $41.4 \%$ $f_{c} A_{s}$.

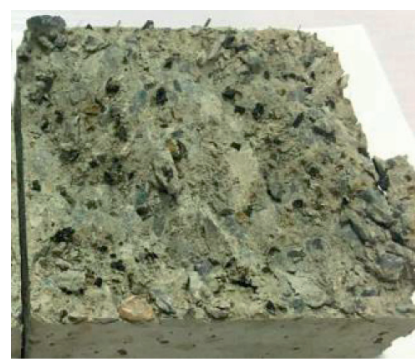

(a)

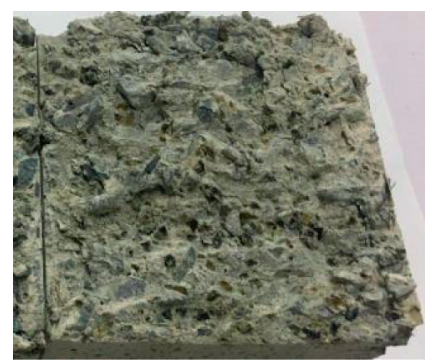

(b)

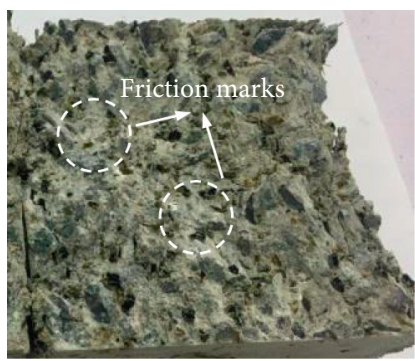

(c)

FIGURE 4: The influence of axial compression ratio on the shear failure section of rubber fiber concrete. (a) $0 \% f_{c} A_{s}$. (b) $20.7 \% f_{c} A_{s}$. (c) $41.4 \%$ $f_{c} A_{s}$.

and will form vertical cracks in the axial loading direction (i.e., the failure mode is formed under the coupled action of compression and shear in this situation).

As shown in Figure 4, when the axial compression ratio was $0 \% f_{c} A_{s}$, the shear failure section of rubber fiber concrete appeared to be uneven, and was accompanied by a small amount of concrete slags. When the axial compression ratio was increased to $20.7 \% f_{c} A_{s}$, the shear failure section of rubber fiber concrete tended to become flattened, and was accompanied by more concrete slags; meanwhile, the friction marks on the shear failure section were deepened. When the axial compression ratio was further increased to $41.4 \% f_{c} A_{s}$, the shear failure section of rubber fiber concrete appeared to be even, and was accompanied by a large amount of concrete slags; meanwhile, the friction marks on the shear failure section were further deepened, with dropping of concrete blocks. This is mainly attributed to the friction caused by the interaction between shear failure sections under the effect of axial compression. The higher the axial compression, the more obvious the friction marks on the shear failure sections are. Under axial compression, the shear plastic deformation capacity of concrete is greatly improved; as a consequence, the shear stress is more likely to form a uniform stress state, which eventually leads to the observed failure mode.

3.1.2. Influence of Rubber Particles and Fibers. To examine the influence of rubber particles and fibers on the shear failure mode of rubber fiber concrete, the $0 \% f_{c} A_{s}$ working condition was selected as the example for analyzing the effects of rubber particles and fibers on the concrete shear failure mode and shear failure section, as shown in Figures 5 and 6 , respectively.

As shown in Figure 5, for specimen C-0\%-0\%, the shear failure mode exhibited a relatively straight main crack, accompanied by 1-2 oblique micro-cracks. For specimen C-30\%-0\%, the shear failure mode showed a fluctuating main crack, which was accompanied by 1-2 oblique microcracks. For specimen C-30\%-0.6\%, the failure crack in the shear direction was slightly fluctuating (between the situations of the other two types of concrete) but there was basically no oblique micro-crack. The underlying mechanism may be explained as follows. The addition of rubber particles forms micropores inside the concrete specimen. Due to the random distribution of rubber particles, the shear failure mode shows a certain level of randomness accordingly, and the main crack in the shear direction appears to be relatively un-straight. When the specimen contains both rubber particles and fibers, the fibers will exert a certain anticracking and anti-tensile effect on the concrete, so that there is basically no oblique micro-crack upon shear failure. Meanwhile, compared to the concrete specimen containing only $30 \%$ of rubber particles (C-30\%-0\%), the failure crack of C-30\%-0.6\% in the shear direction appears to be straight.

As shown in Figure 6, rubber particles and fibers have an obvious effect on the shear failure section of concrete. For specimen C-0\%-0\%, the shear failure section showed a stratification phenomenon and appeared to be relatively flat. 


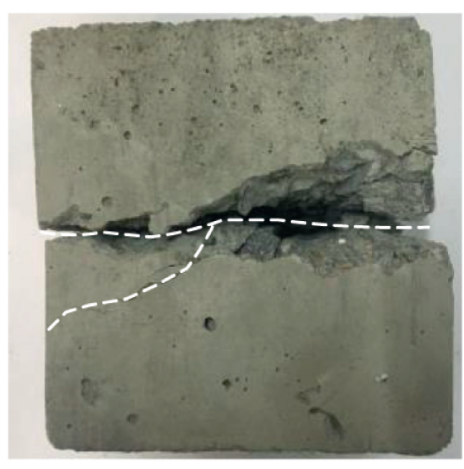

(a)

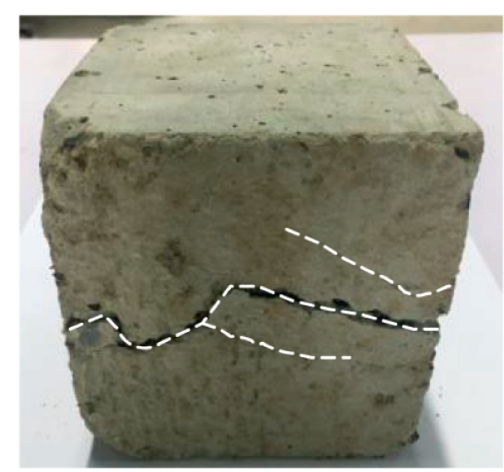

(b)

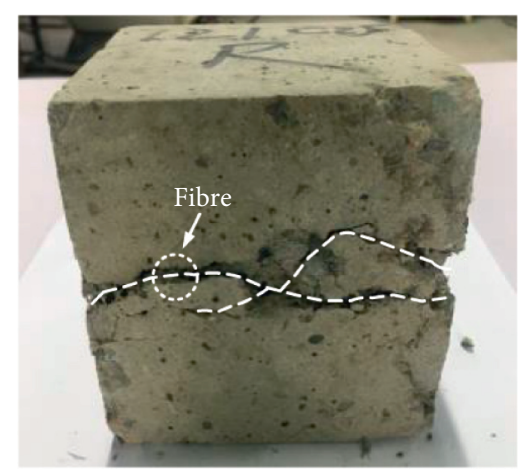

(c)

FIGURE 5: The influence of rubber particles and fibers on the shear failure mode of rubber fiber concrete. (a) C-0\%-0\%. (b) C-30\%-0\%. (c) C$30 \%-0.6 \%$.

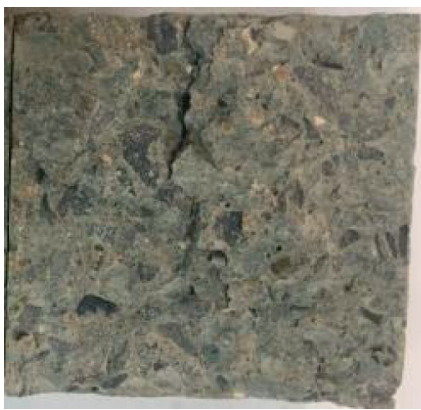

(a)

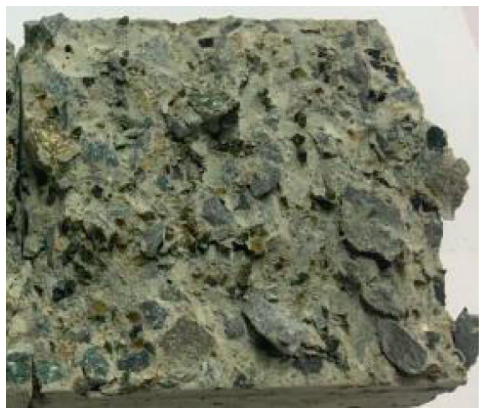

(b)

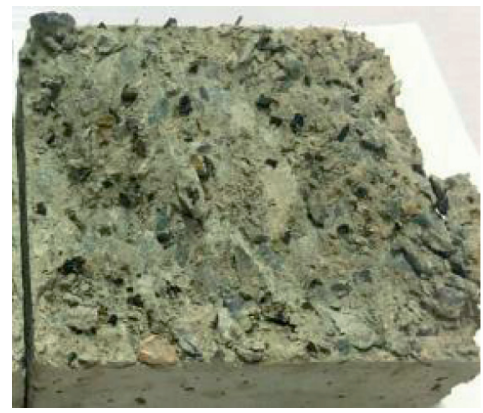

(c)

Figure 6: The influence of rubber particles and fibers on the concrete shear failure section. (a) C-0\%-0\%. (b) C-30\%-0\%. (c) C-30\%-0.6\%.

For specimen C-30\%-0\%, the shear failure section involved dropping of a certain amount of concrete slags and rubber particles, and the shear failure section was relatively uneven. For specimen C-30\%-0.6\%, the shear failure section also involved dropping of a small amount of rubber particles, and the flatness of the shear failure section was between the other two situations. The underlying mechanism for these observations is the same as the mechanism of the influence of rubber particles and fibers on the failure mode in the shear direction.

3.2. Stress-Strain Curve. Based on the three different compression-shear combined loading conditions in this study, the time history curves and shear stress-strain curves of the axial displacement coefficient under different axial compression ratios were obtained, as shown in Figures 7 and 8.

The analysis of the axial deformation time-history curve of concrete under the compression-shear combined stress condition can effectively validate the influence of the rotating and bending effects on the experiment under the compression-shear condition and elaborate the concrete shear failure process from the perspective of deformation. It is noteworthy that, for the axial compression ratio of $0 \% f_{c} A_{s}$, the axial deformation data could not be collected due to equipment limitations. Under the compression-shear combined loading condition, the time history curves of the axial displacement variation coefficients of the three different rubber fiber concrete specimens were obtained as shown in Figure 7.

In accordance with the time history curve of the axial displacement variation coefficient of rubber fiber concrete as shown in Figure 7, it can be seen that the development trend of the time history curve of the three different concrete specimens was basically consistent, which can be divided into two stages. The first stage is the constant stage, during which the axial displacement variation coefficient is stabilized at about 1 , indicating that the concrete shear failure section has no displacement yet, the specimen has not failed and has not exhibited any rotating or bending effects under the shear loading condition. The second stage is the changing stage of the axial displacement variation coefficient, during which the axial displacement variation coefficient and the actual displacement increase gradually with time, indicating that the specimen has shown shear failure with dislocation on the shear failure section, which results in the gradual increase of axial deformation. Based on the comparative analysis of the time history curves of the axial displacement variation coefficient of three different rubber fiber concretes, it is found that C-0\%-0\% had a relatively short shear failure time, weak plastic deformation ability, and high interface axial dislocating displacement. Therefore, it can be 


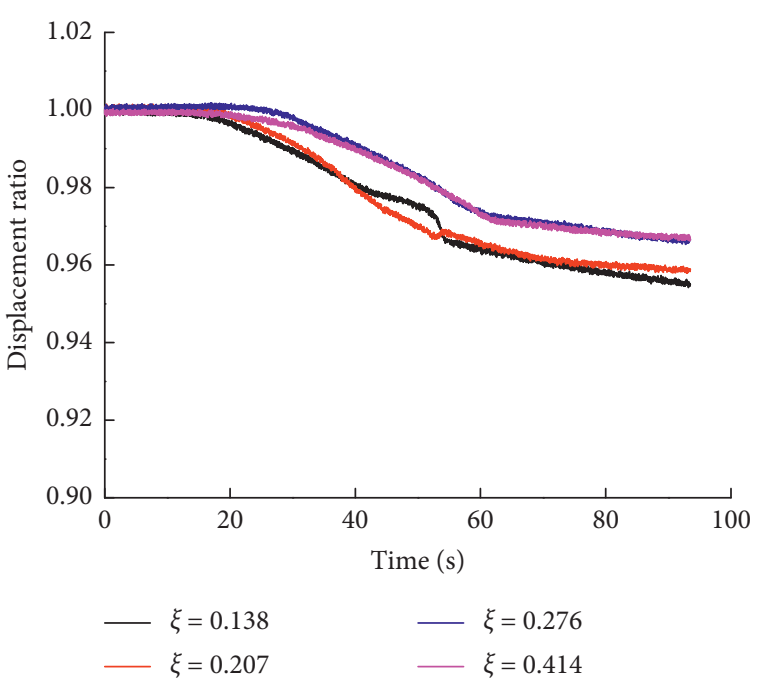

(a)

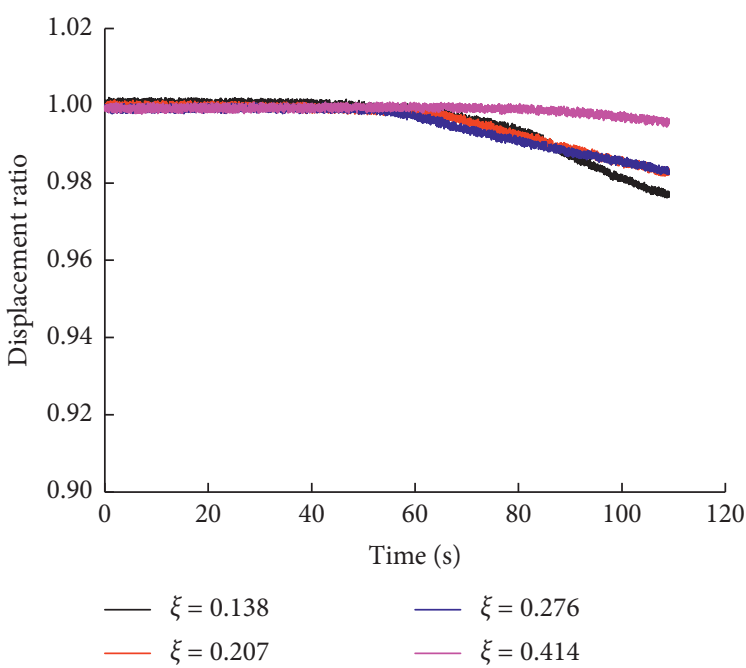

(b)

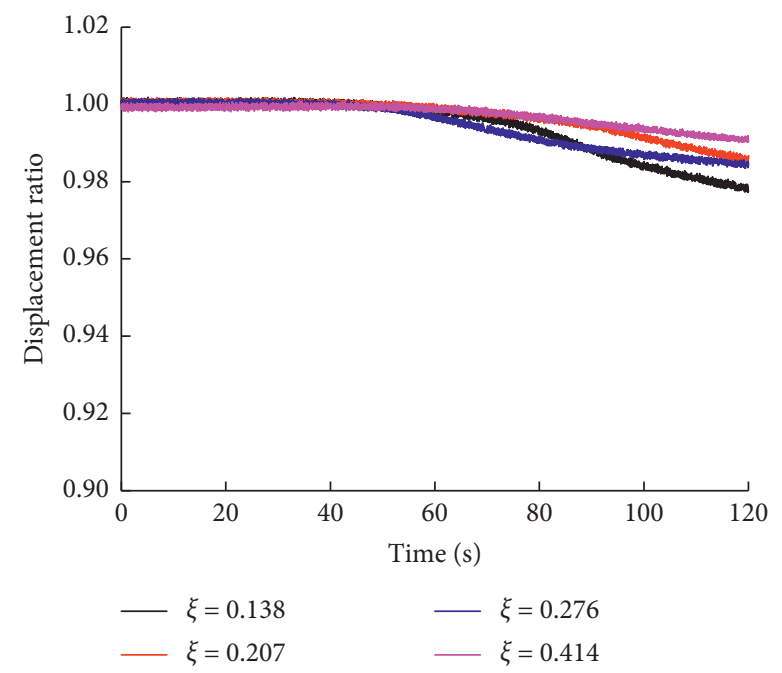

(c)

Figure 7: The time history curve of the axial displacement variation coefficient of rubber fiber concrete. (a) C- $0 \%-0 \%$. (b) C-30\%-0\%. (c) C$30 \%-0.6 \%$.

concluded that the rotating and bending effect during the concrete compression-shear test did not affect the data accuracy in this study, and the analysis findings were credible.

From Figure 8, it can be found that the development trends of the transverse shear stress-strain curves of the three different rubber fiber concretes were basically consistent, which can be divided into three stages: the rising stage, that is, the shear stress increases in a nearly linear relationship with the increase of the shear strain; the declining stage, that is, the shear stress shows an obvious downward trend with the increase of the shear strain; and the stabilizing stage, that is, the shears tress becomes stabilized with the increase of the shear strain. However, when the lateral stress was $0 \% f_{c} A_{s}$, the shear stress-strain curve did not consist of the stabilizing stage, which is due to the fact that the shear stress during the stabilizing stage is formed by the friction generated by the mutual dislocation between the shear surfaces. In accordance with the preliminary analysis of the shear stress-strain curves of rubber fiber concrete under different working conditions, it can be seen that the shear stress and the shear strain were both increased gradually with the increase of the axial compression ratio. At the same axial compression ratio, the shear stress of C-0\%-0\% was higher than that of the other two working conditions, while its shear strain was lower than that of the other two working conditions. In accordance with the analysis of the declining stage of the shear stress-strain curve, C- $0 \%$ $0 \%$ showed relatively lower plastic deformation ability.

\subsection{Mechanical Parameters}

3.3.1. Peak Stress. In accordance with the shear stress-strain curves of the three different rubber fiber concretes, the shear stress values under different axial compressive stresses were obtained, as shown in Figure 9. 


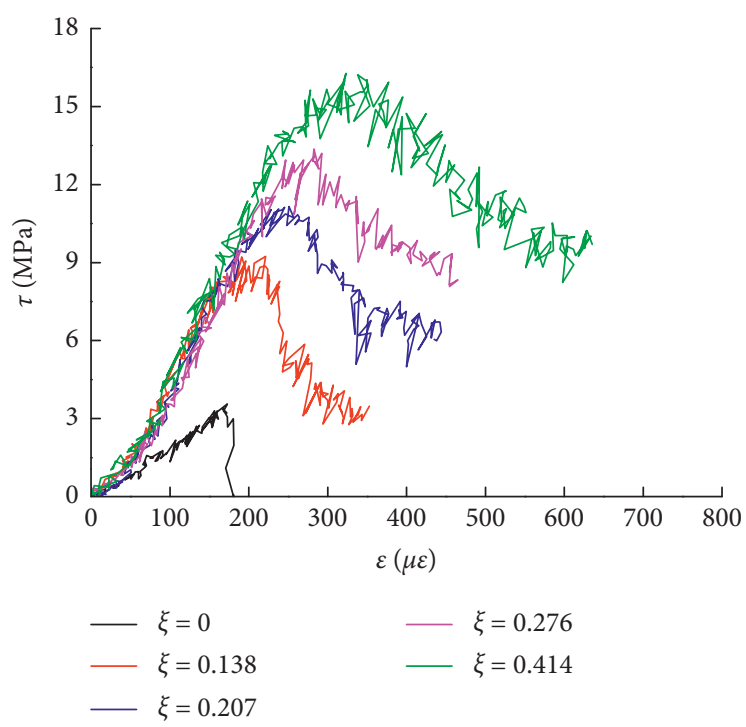

(a)

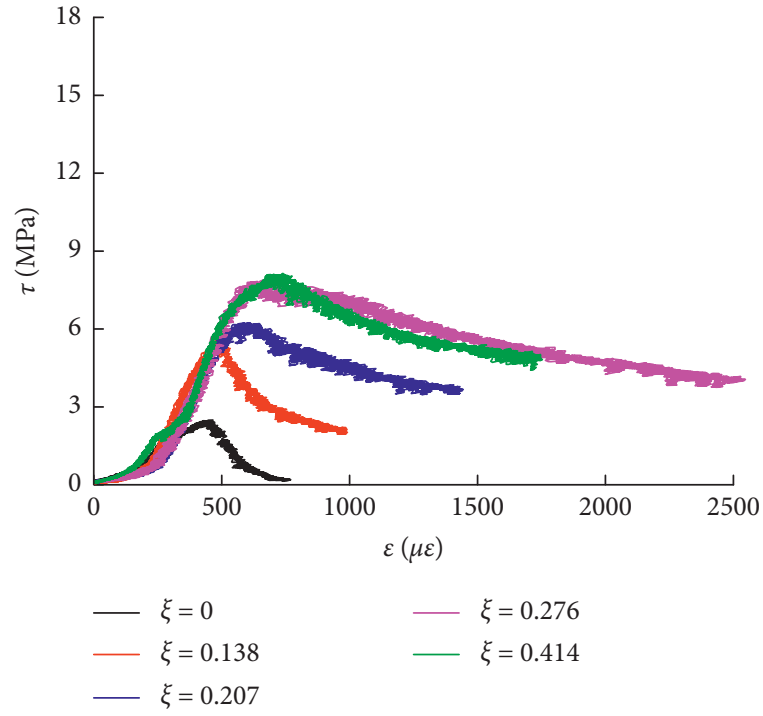

(b)

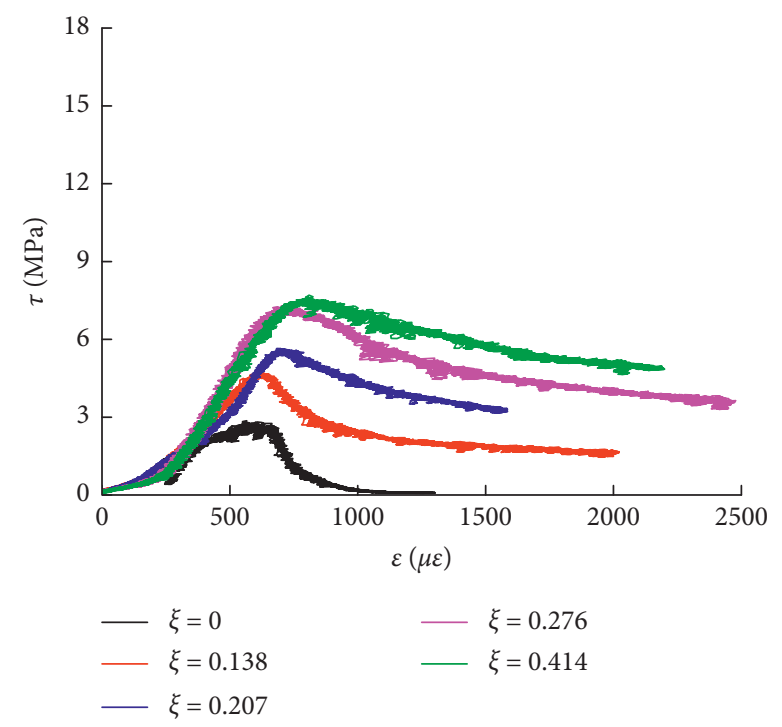

(c)

Figure 8: The shear stress-strain curve of rubber fiber concrete. (a) C-0\%-0\%. (b) C-30\%-0\%. (c) C-30\%-0.6\%.

From Figure 9, it can be seen that, for specimen C-0\%$0 \%$, the shear stress was increased from $3.56 \mathrm{MPa}$ to 16.27 $\mathrm{MPa}$ as the axial compressive stress increased from $0 \mathrm{MPa}$ to $8.10 \mathrm{MPa}$; for specimen C-30\%-0\%, the shear stress was increased from $2.50 \mathrm{MPa}$ to $8.14 \mathrm{MPa}$ as the axial compressive stress increased from $0 \mathrm{MPa}$ to $4.54 \mathrm{MPa}$; for specimen C-30\%- $0.6 \%$, the shear stress was increased from $2.86 \mathrm{MPa}$ to $7.70 \mathrm{MPa}$ as the axial compressive stress increased from $0 \mathrm{MPa}$ to $4.82 \mathrm{MPa}$. As the axial compression ratio increased from 0 to 0.414 , the shear stress of the three different rubber fiber concretes was increased by 4.57 times, 3.26 times, and 2.69 times, respectively. With the increase of the axial compression ratio, the shear stress of all the specimens was increased gradually, which is mainly due to the significant increase of the mechanical bite and friction at the shear interface of concrete under axial compression.
When the axial compression ratio was increased to about 0.3 , the increasing amplitude of the shear stress began to decrease. This is mainly because a high axial compression will cause a certain level of damage to the concrete. Such damage, coupled with the mechanical bite and friction under axial compression, will reduce the increasing amplitude of the shear stress. For specimen C-30\%-0\%, the rubber particles weakened the shear surfaces of rubber fiber concrete, and the mechanical bite and friction on the shear surfaces were relatively low under the influence of axial compression. For specimen C-30\%- $0.6 \%$, the fibers reduced the workability of the concrete, which further weakened the shear surfaces of rubber fiber concrete to a certain extent; consequently, the increasing amplitude of shear stress of C-30\%-0.6\% was the lowest under lateral compression. In summary, the increasing amplitude of shear stress under the action of axial 


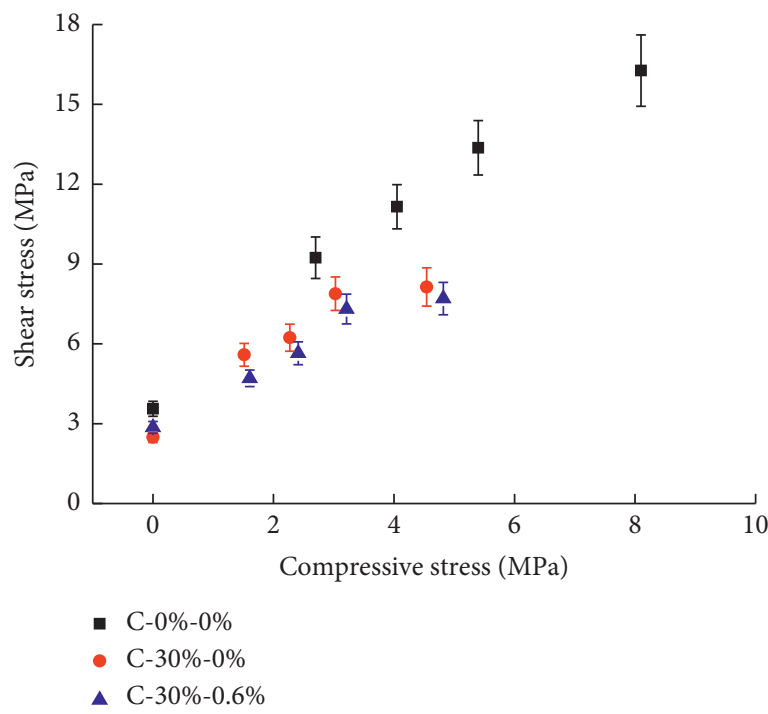

(a)

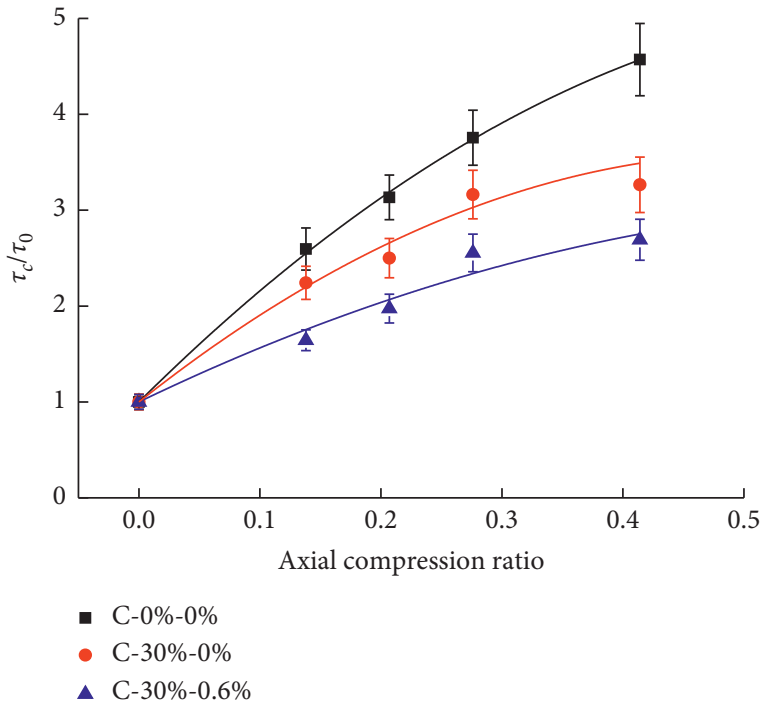

(b)

Figure 9: The relationship between the axial compression stress of rubber fiber concrete and the shear action. (a) Axial compression stress and shear stress. (b) Axial compression ratio and shear stress variation coefficient.

compressive stress was ranked in the following sequence: C- $0 \%-0 \%>$ C- $30 \%-0 \%>$ C-30\%- $0.6 \%$.

When the axial compression ratio was $0 \% f_{c} A_{s}$, the shear stress of specimen C-0\%-0\%, C-30\%-0\%, and C-30\%- $0.6 \%$ was $3.56 \mathrm{MPa}, 2.49 \mathrm{MPa}$, and $2.86 \mathrm{MPa}$, respectively. The addition of rubber particles significantly weakened the shear stress of concrete. For specimen C-30\%-0\%, the shear stress was reduced by $30.06 \%$. This is mainly because rubber particles weakened the shear surfaces of the concrete, leading to the decrease of concrete shear stress. After adding fibers into the concrete (C-30\%-0.6\%), the concrete shear stress was increased by $14.86 \%$, which is mainly attributed to the increase of shear stress caused by the bridging effect of fibers.

In accordance with the development and variation trends of the axial compressive stress and shear stress of the three different types of rubber fiber concrete, a binary linear equation model was proposed to describe the relationship between the axial compressive stress ratio $\sigma / f_{c}$ and the shear stress ratio $\tau / \tau_{0}$, as shown in

$$
\frac{\tau}{\tau_{0}}=1+a \times \frac{\sigma}{f_{c}}+b \times\left(\frac{\sigma}{f_{c}}\right)^{2},
$$

where $\sigma$ is the axial compressive stress of rubber fiber concrete, unit: $\mathrm{MPa} ; f_{c}$ is the compressive strength of rubber fiber concretes, unit: $\mathrm{MPa}$ (in this study, the compressive strength of C-0\%-0\%, C-30\%-0\%, and C-30\%-0.6\% is 19.56 $\mathrm{MPa}, 10.97 \mathrm{MPa}$, and 11.64 $\mathrm{MPa}$, respectively); $\tau$ is the shear stress of rubber concrete, unit: $\mathrm{MPa} ; \tau_{0}$ is the pure shear stress of rubber concrete, unit: $\mathrm{MPa}$.

By applying the experimental data of this study to conduct mathematical regression analysis based on equation (1), the model expression for $\sigma / f_{c}-\tau / \tau_{0}$ and the mathematical regression equations as shown in Figure 9(b) and the following equations were obtained:

$$
\begin{gathered}
\mathrm{C}-0 \%-0 \% \frac{\tau}{\tau_{0}}=1+12.5285 \times \frac{\sigma}{f_{c}}-9.4383 \times\left(\frac{\sigma}{f_{c}}\right)^{2}, \quad R^{2}=0.9998, \\
\mathrm{C}-30 \%-0 \% \frac{\tau}{\tau_{0}}=1+10.0175 \times \frac{\sigma}{f_{c}}-9.6698 \times\left(\frac{\sigma}{f_{c}}\right)^{2}, \quad R^{2}=0.9978, \\
\mathrm{C}-30 \%-0.6 \% \frac{\tau}{\tau_{0}}=1+6.0843 \times \frac{\sigma}{f_{c}}-4.4745 \times\left(\frac{\sigma}{f_{c}}\right)^{2}, \quad R^{2}=0.9945 .
\end{gathered}
$$

From Figure 9(b) and equations (2)-(4), it can be seen that equation (1) can effectively describe the relationship between the axial compressive stress and shear stress for all the three different types of rubber fiber concrete, suggesting that the shear stress of rubber fiber concrete increases gradually with the increase of the axial compression ratio. 
When the axial compression ratio is relatively high, the changing amplitude of shear stress gradually becomes flattened with the increase of the axial compression ratio.

3.3.2. Residual Stress. Under the compression-shear combined condition, the counterforce of the transverse shear loading action is mainly provided by the friction between the shear failure sections in the third stage of the shear load displacement curve. In accordance with the experimental data in this study, the relationship between the axial action and residual action of rubber fiber concrete was obtained, as shown in Figure 10.

From Figure 10, it can be seen that the residual stress of C-0\%-0\% was increased from $0 \mathrm{MPa}$ to $4.03 \mathrm{MPa}$ as the axial compressive stress increased from $0 \mathrm{MPa}$ to $8.10 \mathrm{MPa}$; the residual stress was 2.05 times of the pure shear stress. The residual stress shows a gradually increasing trend with the increase of the lateral compressive stress. When the lateral compressive stress was higher than $27.6 \% f_{c} A_{s}$, the increasing amplitude of the residual stress tended to become flattened. The residual stress of C-30\%-0\% was increased from $0 \mathrm{MPa}$ to $4.74 \mathrm{MPa}$ as the axial compressive stress increased from $0 \mathrm{MPa}$ to $3.03 \mathrm{MPa}$; the residual stress was 1.90 times of the pure shear stress. For specimen C-30\%-0\%, when the lateral compressive stress was higher than $27.6 \% f_{c} A_{s}$, the residual stress was gradually decreased with the increase of the lateral compressive stress. The residual stress of C-30\%- $0.6 \%$ was increased from $0 \mathrm{MPa}$ to $4.99 \mathrm{MPa}$ as the axial compressive stress increased from $0 \mathrm{MPa}$ to $3.21 \mathrm{MPa}$; the residual stress was 1.74 times of the pure shear stress, suggesting the same variation trend as that of C-30\%-0.6\%. From the overall trend, the increasing amplitude of the residual stress affected by the lateral compressive stress was ranked in the following sequence: C- $0 \%-0 \%>$ C-30\%-0\%>C-30\%-0.6\%. The underlying mechanism behind the changing trend observed above is attributed to the combined effects of the following facts: (1) rubber particles have a significant weakening effect on the shear surfaces; (2) fibers can decrease the concrete workability; (3) the axial compressive stress reduces the friction on the shear surface; (4) both rubber particles and fibers can improve the plastic deformation ability of concrete.

3.3.3. Peak Strain. In accordance with the shear stress-strain curves of the three different rubber fiber concretes under the compression-shear combined condition, the shear strains (the strain value corresponding to the shear stress) under different axial compression ratios were extracted as shown in Figure 10, which were used to analyze the effects of rubber, fiber, and axial compression ratio on the shear strain.

From Figure 11, it can be seen that the shear strain of all the three rubber fiber concretes was increased significantly with the increase of the axial compressive stress. This is mainly because the axial compressive stress gradually increased the plastic deformation ability of the rubber fiber concrete. In addition, the shear strain of C- $0 \%-0 \%, \mathrm{C}-30 \%-$ $0 \%$, and C-30\%-0.6\% was ranked in an ascending order, mainly due to the reason that the deformation ability of rubber particles is higher than that of aggregate components while fibers can increase the plastic deformation ability of concrete. For specimen C-0\%-0\%, the shear strain was increased from $173 \mu \varepsilon$ to $323 \mu \varepsilon$, suggesting an increase of $83.52 \%$; for specimen C-30\%-0\%, the shear strain was increased from $466 \mu \varepsilon$ to $739 \mu \varepsilon$, suggesting an increase of $58.58 \%$; for specimen C-30\%-0.6\%, the shear strain was increased from $566 \mu \varepsilon$ to $810 \mu \varepsilon$, suggesting an increase of $43.11 \%$. In comparison, the shear strain of specimen C-30\%$0.6 \%$ had the highest increasing amplitude affected by the axial compressive stress, while the shear strain of specimen C-0\%-0\% had the lowest increasing amplitude.

\section{Failure Mechanism and Failure Criteria}

4.1. Failure Mechanism. In order to further elaborate the failure mechanism of rubber fiber concrete, the scanning electron microscope (SEM) and X-ray diffractometer (XRD) were used to test the internal structure and composition of rubber fiber concrete. The SEMs of the three different rubber fiber concretes are shown in Figure 12.

From Figure 12, it can be seen that the coarse aggregates of specimen C-0\%-0\% exhibited a significantly higher compactness, but the compactness on the contact interface between the coarse aggregates and mortar was lower. Upon shear failure, the damage mainly occurred on the interface between the coarse aggregates and mortar. For specimen C-30\%-0\%, the compactness of the contact interface between rubber particles and mortar was significantly lower, while the porosity of rubber particles was significantly higher than that of mortar and coarse aggregates. Consequently, the shear stress of the specimen was significantly decreased and the shear deformation was significantly increased. Upon failure, a certain amount of rubber particles dropped off from the specimen. For C-30\%-0.6\%, the fibers were distributed inside the mortar, and there were a certain number of pores on the contact interface between the mortar and fibers, which weakened the compactness of the mortar. The main reason is that although the distribution of fibers reduces the workability and fluidity of the concrete mixture, with the fibers inside the mixture, the bonding effect between the fibers and mortar exerts an inhibitory effect on the generation and development of cracks during the shear process to a certain extent. Under the coupled effect of the two factors, the shear stress of specimen C-30\%-0.6\% showed a smaller variation compared to specimen C-30\%$0 \%$.

4.2. Failure Criterion. When concrete is under the compression-shear combined action, its compressive stress $\sigma$ and shear stress $\tau$ can be converted into the first principal stress $\sigma_{1}$, the second principal stress $\sigma_{2}$ and the third principal stress $\sigma_{3}$ through the following equations [22, 30]:

$$
\begin{aligned}
& \sigma_{1}=\frac{\sigma}{2}+\sqrt{\left(\frac{\sigma}{2}\right)^{2}+\tau^{2}} \\
& \sigma_{2}=0
\end{aligned}
$$




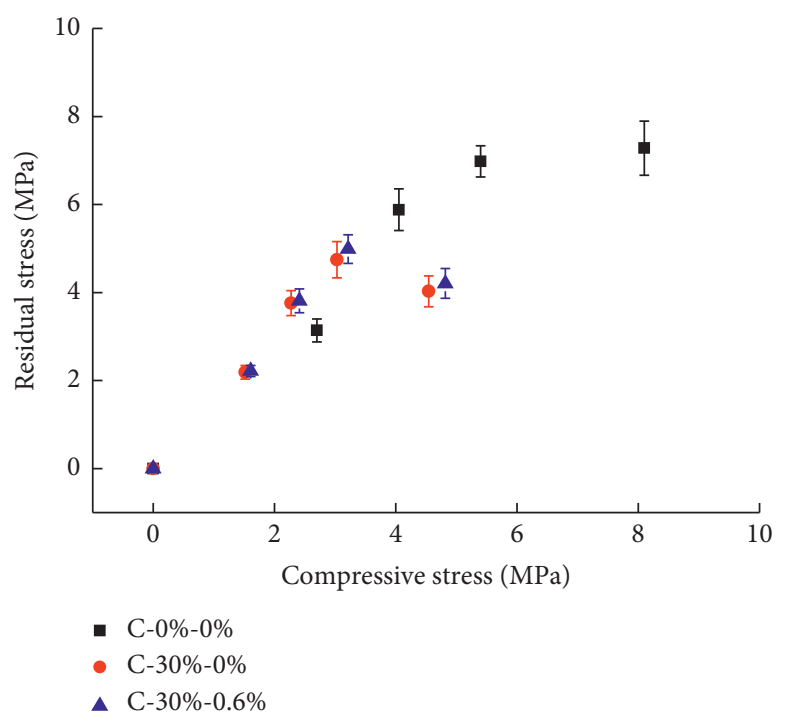

(a)

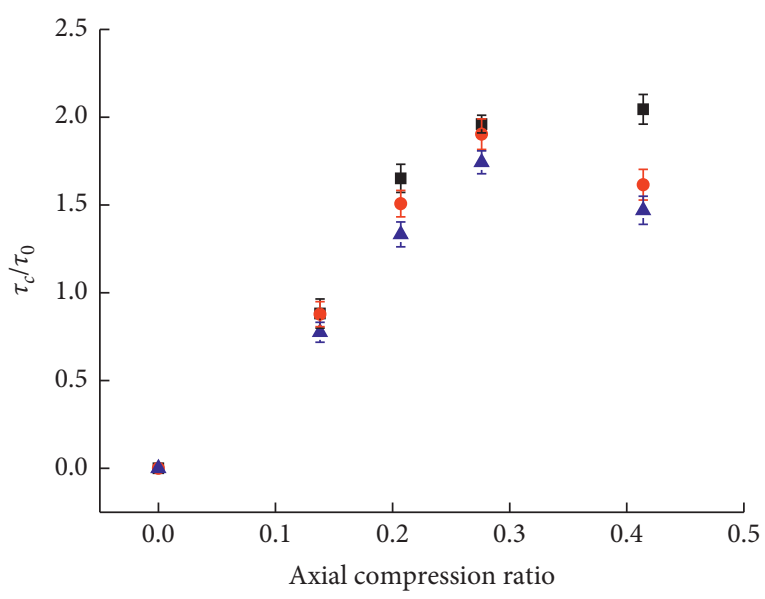

- $\mathrm{C}-0 \%-0 \%$

- $\mathrm{C}-30 \%-0 \%$

- $\mathrm{C}-30 \%-0.6 \%$

FIGURE 10: The relationship between the axial compressive stress and residual action of rubber fiber concrete. (a) Axial compressive stress and residual stress. (b) Axial compression ratio and residual stress variation coefficient.

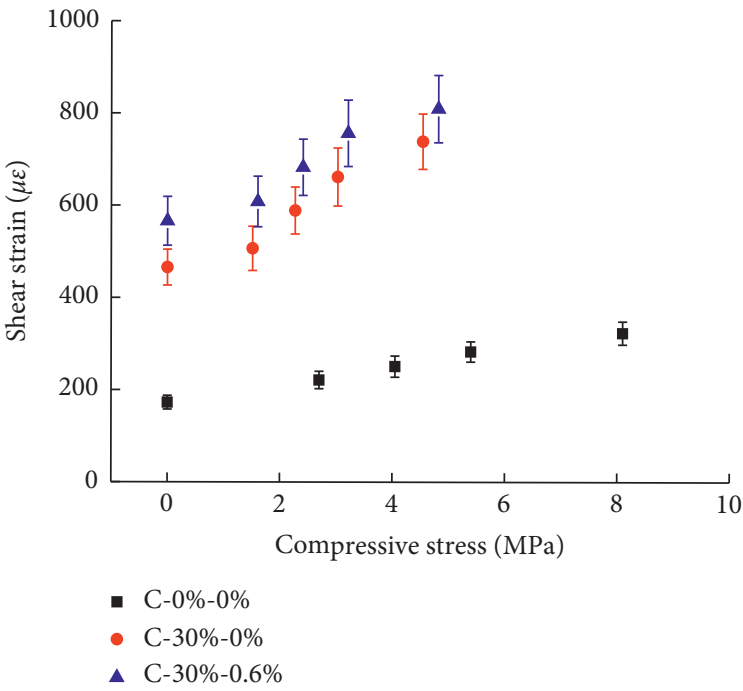

(a)

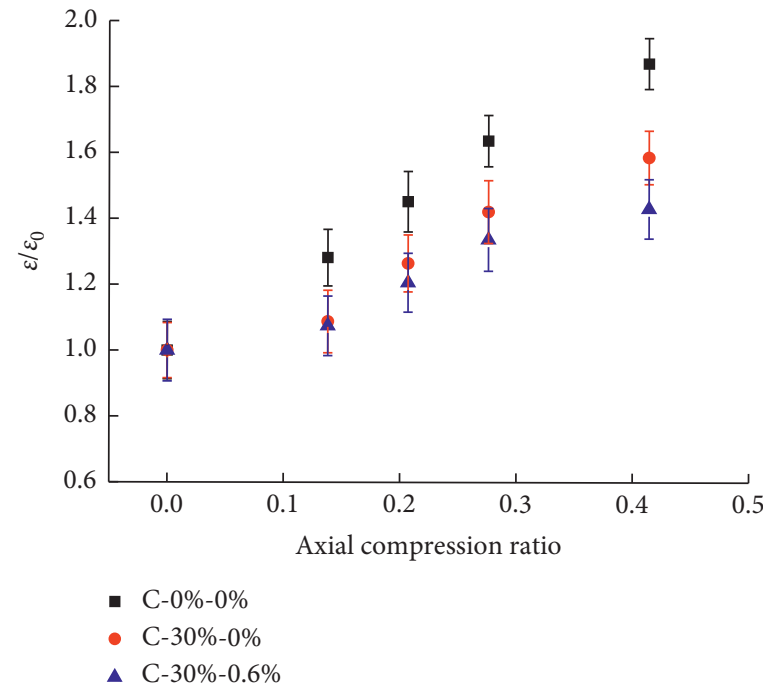

(b)

FIGURE 11: The relationship between the axial compressive stress and shear strain of rubber fiber concrete. (a) Axial compressive stress and shear strain. (b) Axial compression ratio and shear strain variation coefficient.

$$
\sigma_{3}=\frac{\sigma}{2}-\sqrt{\left(\frac{\sigma}{2}\right)^{2}+\tau^{2}}
$$

4.2.1. Failure Criterion of Principal Stress Space. In order to examine the failure criteria of principle stress space for the three different rubber fiber concretes, equations (5)-(7) were applied to calculate the space principal stress based on the compression-shear experiment data of rubber fiber concrete obtained in this study. The expressions of principal stress space under the compression-shear combined action were obtained as shown in Figure 13.

From Figure 13, it can be seen that the nondimensional processing coefficient of the first principal stress of rubber fiber concrete had a linear relationship with that of the third principal stress. Meanwhile, the development trends and patterns of the nondimensional processing coefficients of the first principal stress and third principal stress remained consistent across all the three different rubber fiber concretes. Therefore, the failure criterion equations of the principal stress space for the three types of rubber fiber 


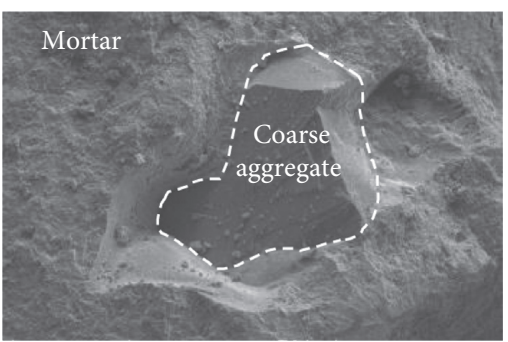

(a)

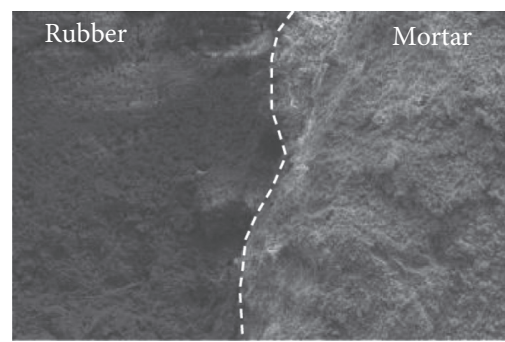

(b)

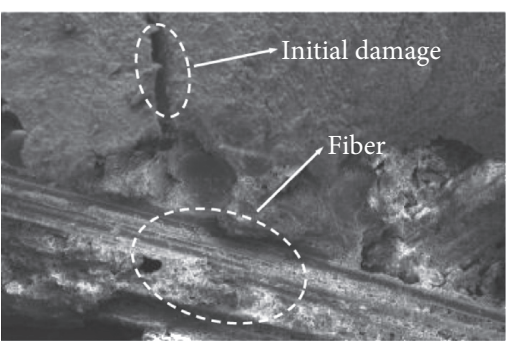

(c)

Figure 12: SEM of rubber fiber concrete. (a) C-0\%-0\%. (b) C-30\%-0\%. (c) C-30\%-0.6\%.

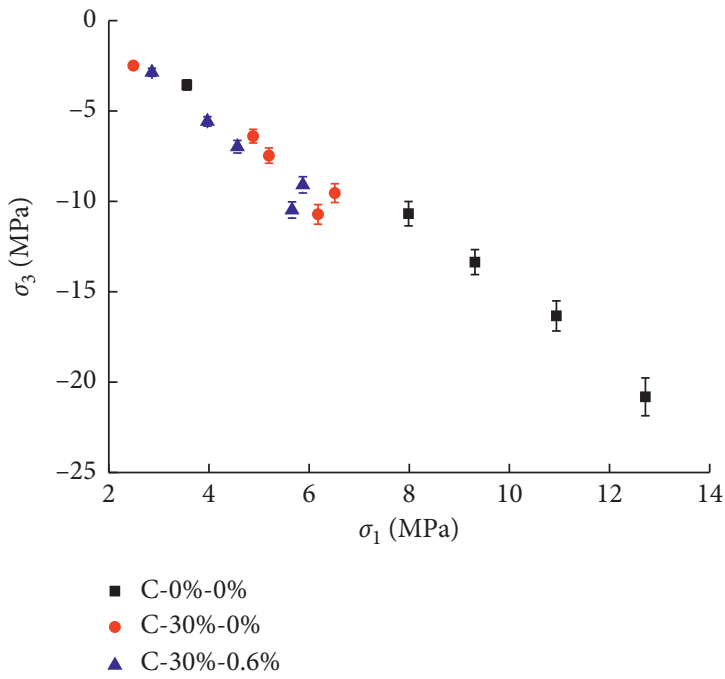

(a)

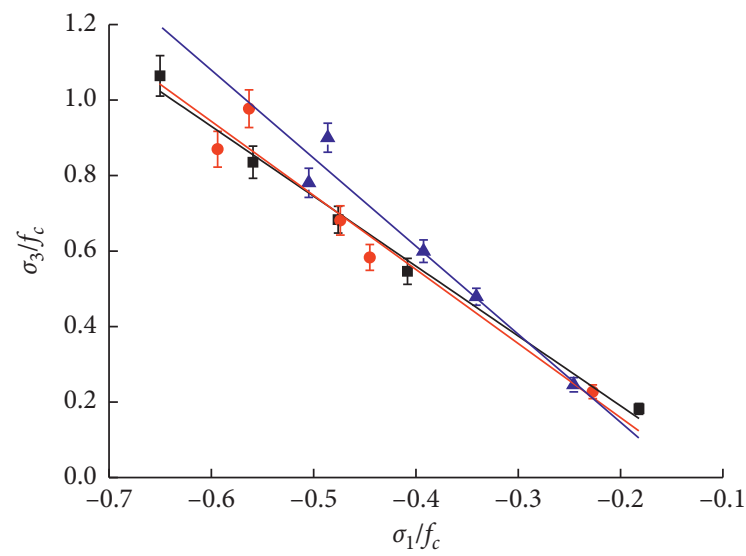

- $\mathrm{C}-0 \%-0 \%$

- $\mathrm{C}-30 \%-0 \%$

- $\mathrm{C}-30 \%-0.6 \%$

(b)

FIGURE 13: The relationship between the first principal stress and the third principal stress of rubber fiber concrete. (a) The first principal stress and the third principal stress. (b) The first principal stress ratio and the third principal stress ratio.

concrete under compression-shear combined action were proposed as shown in

$$
\frac{\sigma_{3}}{f_{c}}=a_{1}+a_{2} \times \frac{\sigma_{1}}{f_{c}} .
$$

By performing mathematical regression analysis based on the experiment data of the first principal stress and third principal stress of the rubber fiber concrete under the compression-shear combined action, the diagram and equations for the failure criterion of the principal stress space were obtained as shown in Figure 13 and the following equations:

$$
\begin{gathered}
\mathrm{C}-0 \%-0 \% \frac{\sigma_{3}}{f_{c}}=-0.1803-1.8510 \times \frac{\sigma_{1}}{f_{c}}, \quad R^{2}=0.9881, \\
\mathrm{C}-30 \%-0 \% \frac{\sigma_{3}}{f_{c}}=-0.2351-1.9597 \times \frac{\sigma_{1}}{f_{c}}, \quad R^{2}=0.9256,
\end{gathered}
$$

$$
\mathrm{C}-30 \%-0.6 \% \frac{\sigma_{3}}{f_{c}}=-0.3213-2.3405 \times \frac{\sigma_{1}}{f_{c}}, \quad R^{2}=0.9324 .
$$

From Figure 13 and equations (9)-(11), it can be seen that the failure criterion proposed based on the principal stress space as shown in equation (8) has good applicability for all the three different rubber fiber concretes under the compression-shear combined action. The failure criterion can effectively describe the failure patterns of the three different rubber fiber concretes under compression and shear.

4.2.2. Failure Criterion of Octahedral Stress Space. In the multiaxial stress state of concrete, the failure criterion based on the octahedral stress space can well describe the spatial stress relationship of concrete. The expressions of normal stress $\sigma_{\text {oct }}$ and shear stress $\tau_{\text {oct }}$ can be calculated from the following equations [31]: 


$$
\begin{aligned}
& \sigma_{\mathrm{oct}}=\frac{1}{3}\left(\sigma_{1}+\sigma_{2}+\sigma_{3}\right), \\
& \tau_{\mathrm{oct}}=\frac{1}{3} \sqrt{\left(\sigma_{1}-\sigma_{2}\right)^{2}+\left(\sigma_{2}-\sigma_{3}\right)^{2}+\left(\sigma_{3}-\sigma_{1}\right)^{2}} .
\end{aligned}
$$

In accordance with the examination of the failure criterion of ordinary concrete and lightweight aggregate concrete under the compression-shear combined action in literature [32], the application of linear function based on the failure criterion of octahedral stress space can more concisely elaborate the failure criterion regularity of concrete than the quadratic function under a low axial compression ratio. But, under a high axial compression ratio, the quadratic function expression shows better accuracy. Based on the compression-shear combined stress tests of the three types of rubber fiber concrete in this study, the expressions as shown in equations (14) and (15) were proposed.

$$
\begin{aligned}
& \frac{\tau_{\mathrm{oct}}}{f_{c}}=a+b \times \frac{\sigma_{\mathrm{oct}}}{f_{c}}, \\
& \frac{\tau_{\mathrm{oct}}}{f_{c}}=c+d \times \frac{\sigma_{\mathrm{oct}}}{f_{c}}+e \times\left(\frac{\sigma_{\mathrm{oct}}}{f_{c}}\right)^{2} .
\end{aligned}
$$

In accordance with the experimental data of rubber fiber concrete under the compression-shear combined action in this paper, mathematical regression analysis was carried out by applying equations (14) and (15), and the failure criterion of the octahedral stress space of rubber fiber concrete under the two expression forms were obtained as shown in Figure 14 and the following equations:

$$
\begin{aligned}
\frac{\tau_{\mathrm{oct}}}{f_{c}} & =-0.1806-4.0349 \times \frac{\sigma_{\mathrm{oct}}}{f_{c}}, \quad R^{2}=0.9748 \\
\mathrm{C}-0 \%-0 \% \frac{\tau_{\mathrm{oct}}}{f_{c}} & =-0.1497-5.6467 \times \frac{\sigma_{\mathrm{oct}}}{f_{c}}+11.6792 \times\left(\frac{\sigma_{\mathrm{oct}}}{f_{c}}\right)^{2}, \quad R^{2}=0.9987 \\
\frac{\tau_{\mathrm{oct}}}{f_{c}} & =-0.2337-3.3315 \times \frac{\sigma_{\mathrm{oct}}}{f_{c}}, \quad R^{2}=0.8900, \\
\mathrm{C}-30 \%-0 \% \frac{\tau_{\mathrm{oct}}}{f_{c}} & =-0.1829-5.9804 \times \frac{\sigma_{\mathrm{oct}}}{f_{c}}+19.1952 \times\left(\frac{\sigma_{\mathrm{oct}}}{f_{c}}\right)^{2}, \quad R^{2}=0.9704 \\
\frac{\tau_{\mathrm{oct}}}{f_{c}} & =-0.2126-2.8558 \times \frac{\sigma_{\mathrm{oct}}}{f_{c}}, \quad R^{2}=0.9394, \\
\mathrm{C}-30 \%-0.6 \% \frac{\tau_{\mathrm{oct}}}{f_{c}} & =-0.1917-3.9492 \times \frac{\sigma_{\mathrm{oct}}}{f_{c}}+7.9233 \times\left(\frac{\sigma_{\mathrm{oct}}}{f_{c}}\right)^{2}, \quad R^{2}=0.9417 .
\end{aligned}
$$

From Figure 14 and equations (16)-(21), it can be seen that the linear and quadratic failure criterion equations proposed based on the octahedral stress space have good applicability to the description of the failure criterion relationship of rubber fiber concrete under the compressionshear combined action. More specifically, the quadratic equation model has better applicability than the linear equation model for describing the multiaxial failure criterion of rubber fiber concrete under the compression-shear combined stress environment at a high axial compression ratio.

According to the model analysis based on equations (2)-(4), (9)-(11), and (16)-(21), the concrete shear stress shows a significant increasing trend as the axial compressive stress increases. Specifically, the increasing amplitude of shear stress under the influence of axial compressive stress is ranked in a descending sequence from ordinary concrete, rubber concrete, to rubber fiber concrete. The effect of axial compressive stress significantly improves the mechanical occlusion and friction between the aggregates at the shear interface, which increases the concrete shear stress. When the axial compressive stress is high, the concrete will develop a certain amount of damage, and thus, the increasing amplitude of shear stress is gradually decreased as the axial compression stress increases at a relatively high axial compression. Literature [23] shows that the changing patterns of multiaxial mechanical properties of concrete are closely related to the characteristics of the interface transition zone. According to Figure 12, under the influence of rubber particles and fibers, the interface performance between mortar and coarse aggregates is gradually weakened from ordinary concrete, rubber concrete, to rubber fiber concrete. When axial compressive stress is applied, the specimen that is subjected to a stronger weakening effect on the interface performance is prone to greater deformation and damage under the action of axial compression, and thus the increasing amplitude of shear stress will be weakened. Consequently, the increasing amplitude of shear stress under the influence of axial compressive stress is ranked in a descending sequence from ordinary concrete, rubber 


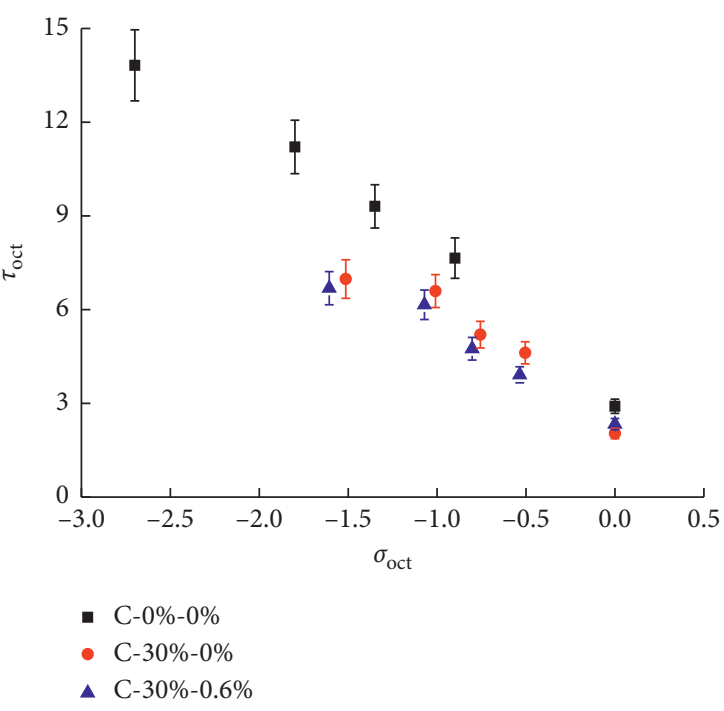

(a)

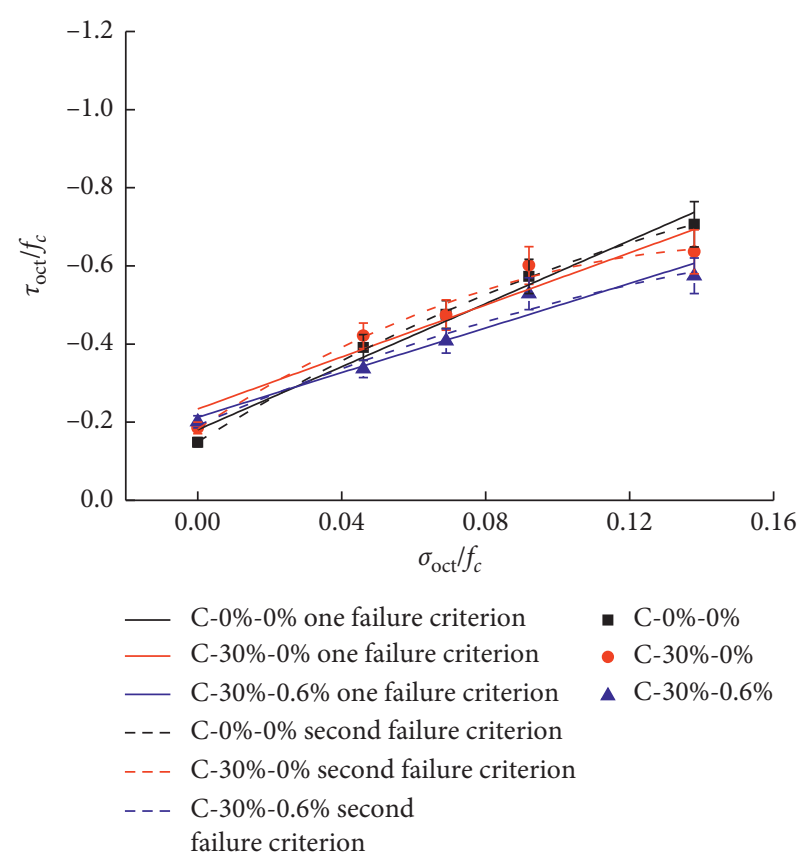

(b)

Figure 14: The octahedral space stress relationship of rubber fiber concrete. (a) Normal stress and shear stress. (b) Octahedral failure criterion.

concrete to, rubber fiber concrete. The changing patterns of model parameters obtained in this paper are consistent with the abovementioned mechanism.

With respect to the compression-shear mechanical properties of rubber fiber concrete, the shear stress can be predicted by the machine learning method. In the present study, the number of data points under consideration is far from enough. Meanwhile, the experimental research on the compressive-shear mechanical properties of rubber fiber concrete has not been reported in the relevant literature, and therefore, a huge amount of test data is needed in the future to support the research in this aspect. The follow-up research shall carry out further experimental research on the shear mechanical properties of rubber fiber concrete by considering more influencing factors such as rubber particle content, fiber content, and axial compression ratio, so as to provide a direct basis for predicting the shear stress of rubber fiber concrete by applying machine learning [33].

\section{Conclusions}

In this paper, an experimental study was carried out on the shear mechanical properties of rubber fiber concrete by considering different axial compression ratios, so as to analyze the influence of the axial compression ratio, rubber, and fiber on the shear mechanical properties of concrete. In summary, the following conclusions were drawn:

(1) With the increase of the axial compression ratio, the cracks of rubber fiber concrete in the shear direction gradually developed into the failure mode of axial cracks intersecting with shear cracks; meanwhile, the concrete slags on the shear failure section were gradually increased and the friction marks were gradually deepened. Due to the presence of rubbers and fibers, the shear failure mode became different across different concrete specimens. The rubber particles increased the randomness of the development of cracks upon concrete failure, while the fibers inhibited the development of diagonal cracks and the dropping of concrete slags.

(2) The increase in the axial compression ratio gradually increased the concrete shear stress and shear strain. Specifically, the shear stress of specimen C-0\%-0\%, C-30\%-0\%, and C-30\%-0.6\% was increased by 4.57 times, 3.26 times, and 2.69 times respectively, and the shear strain was increased by $83.52 \%, 58.58 \%$, and $43.11 \%$, respectively. The influence of the axial compression ratio on the shear stress and shear strain of the three different types of rubber fiber concretes was gradually weakened. The rubber particles reduced the concrete shear stress and significantly increased the shear strain. The fibers had a relatively insignificant effect on the concrete shear stress, but the increase in the shear strain was relatively obvious.

(3) The increase of the axial compression ratio gradually increased the residual stress of rubber fiber concrete. When the axial compression was relatively high, the residual stress of rubber fiber concrete showed a gradually decreasing trend with the increase of the axial compression ratio. Specifically, the ratio between residual stress and pure shear stress for 
specimen C-0\%-0\%, C-30\%-0\%, and C-30\%-0.6\% was $2.05,1.90$, and 1.47 , respectively. The influence of the axial compression ratio on the residual stress of the three different types of rubber fiber concrete showed a gradually decreasing trend.

(4) The failure mechanism of rubber fiber concrete under the compression-shear multiaxial action was examined from both the macroscopic and mesoscopic perspectives. Meanwhile, according to the compression-shear multiaxial test data obtained in this paper, the compression-shear multiaxial failure criterion of rubber fiber concrete was established based on the principal stress space and the octahedral stress space.

\section{Data Availability}

The nature of the data is the experimental data of rubber fiber concrete under the compression-shear combined action. The data used to support the findings of this study are available from the corresponding author upon request.

\section{Conflicts of Interest}

The authors declare that they have no conflicts of interest.

\section{Acknowledgments}

This research was supported by the Key Research and Development and Transformation Projects in Qinghai Province (Grant No. 2021-SF-154). The authors are grateful for the financial support.

\section{References}

[1] F. Aslani, G. Ma, D. L. Yim Wan, and G. Muselin, "Development of high-performance self-compacting concrete using waste recycled concrete aggregates and rubber granules," Journal of Cleaner Production, vol. 182, pp. 553-566, 2018.

[2] Y. Hu, X. Sun, A. Ma, and P. Gao, "An experimental study on the basic mechanical properties and compression size effect of rubber concrete with different substitution rates," Advances in Civil Engineering, vol. 2020, Article ID 8851187, 15 pages, 2020.

[3] J. Lv, Q. Du, T. Zhou, Z. He, and K. Li, "Fresh and mechanical properties of self-compacting rubber lightweight aggregate concrete and corresponding mortar," Advances in Materials Science and Engineering, vol. 2019, Article ID 8372547, 14 pages, 2019.

[4] J. Lv, T. Zhou, Q. Du, and H. Wu, "Effects of rubber particles on mechanical properties of lightweight aggregate concrete," Construction and Building Materials, vol. 91, pp. 145-149, 2015.

[5] F. Aslani, "Mechanical properties of waste tire rubber concrete," Journal of Materials in Civil Engineering, vol. 28, no. 3, Article ID 04015152, 2016.

[6] T. Xie, J. Liang, F. Yang et al., "Basic mechanical properties of recycled rubber fine aggregate concrete," Concrete, vol. 358, no. 2, pp. 99-101, 2016.

[7] M. A. Fadhli, "Properties of concrete containing scrap-tire rubber," International Journal of Engineering Research \& Applications, vol. 7, no. 3, pp. 36-42, 2017.
[8] A. R. Khaloo, M. Dehestani, and P. Rahmatabadi, "Mechanical properties of concrete containing a high volume of tire-rubber particles," Waste Management, vol. 28, no. 12, pp. 2472-2482, 2008.

[9] A. O. Atahan and A. Ö. Yücel, "Crumb rubber in concrete: static and dynamic evaluation," Construction and Building Materials, vol. 36, pp. 617-622, 2012.

[10] K. Coventry, A. Richardson, and E. Diaz, "Impact resistance of concrete-using slit rubber from tyres," Journal of Harbin Institute of Technology, vol. 21, no. 4, pp. 43-46, 2015.

[11] A. Nkem Ede, A. O. Ige, and A. Oluwabambi Ige, "Optimal polypropylene fiber content for improved compressive and flexural strength of concrete," IOSR Journal of Mechanical and Civil Engineering, vol. 11, no. 3, pp. 129-135, 2014.

[12] R. Bagherzadeh, A. H. Sadeghi, and M. Latifi, "Utilizing polypropylene fibers to improve physical and mechanical properties of concrete," Textile Research Journal, vol. 82, no. 2 , pp. 88-96, 2012.

[13] M. R. Arefi and E. Mollaahmadi, "An experimental investigation into the effect of polypropylene fibers on mechanical properties of concrete," in Proceedings of the 7th Asian Symposium on Polymers in Concrete (ASPIC 2012), Istanbul, Turkey, 2012.

[14] N. Banthia and R. Gupta, "Influence of polypropylene fiber geometry on plastic shrinkage cracking in concrete," Cement and Concrete Research, vol. 36, no. 7, pp. 1263-1267, 2006.

[15] C. E. Chalioris and T. A. Panagiotopoulos, "Flexural analysis of steel fibre-reinforced concrete members," Computers and Concrete, vol. 22, no. 1, pp. 11-25, 2018.

[16] V. Guerini, A. Conforti, G. Plizzari, and S. Kawashima, "Influence of steel and macro-synthetic fibers on concrete properties," Fibers, vol. 6, no. 3, p. 47, 2018.

[17] V. K. Kytinou, C. E. Chalioris, and C. G. Karayannis, "Analysis of residual flexural stiffness of steel fiber-reinforced concrete beams with steel reinforcement," Materials, vol. 13, no. 12, p. 2698, 2020.

[18] S. Altoubat, A. Yazdanbakhsh, and K. A. Rieder, "Shear behavior of macro-synthetic fiber-reinforced concrete beams without stirrups," ACI Materials Journal, vol. 106, no. 4, pp. 381-389, 2009.

[19] J.-P. Charron, C. Desmettre, and C. Androuët, "Flexural and shear behaviors of steel and synthetic fiber reinforced concretes under quasi-static and pseudo-dynamic loadings," Construction and Building Materials, vol. 238, Article ID 117659, 2020.

[20] V. K. Kytinou, C. E. Chalioris, C. G. Karayannis, and A. Elenas, "Effect of steel fibers on the hysteretic performance of concrete beams with steel reinforcement-tests and analysis," Materials, vol. 13, no. 13, p. 2923, 2020.

[21] H. H. Awan, M. F. Javed, A. Yousaf, F. Aslam, H. Alabduljabbar, and A. Mosavi, "Experimental evaluation of untreated and pretreated crumb rubber used in concrete," Crystals, vol. 11, no. 5, p. 558, 2021.

[22] Z. Yu, Q. Huang, F. Li, Y. Qin, and J. Zhang, "Experimental study on mechanical properties and failure criteria of selfcompacting concrete under biaxial tension-compression," Journal of Materials in Civil Engineering, vol. 31, no. 5, Article ID 04019045, 2019.

[23] A. H. Gandomi, S. K. Babanajad, A. H. Alavi, and Y. Farnam, "Novel approach to strength modeling of concrete under triaxial compression," Journal of Materials in Civil Engineering, vol. 24, no. 9, pp. 1132-1143, 2012.

[24] Y. Chi, L. Xu, G. Mei, N. Hu, and J. Su, "A unified failure envelope for hybrid fibre reinforced concrete subjected to true 
triaxial compression," Composite Structures, vol. 109, no. 6, pp. 31-40, 2014.

[25] B. Ruan, Y. Miao, K. Cheng, and E.-1. Yao, "Study on the small strain shear modulus of saturated sand-fines mixtures by bender element test," European Journal of Environmental and Civil Engineering, vol. 25, no. 1, pp. 28-38, 2021.

[26] Z. He and Y. Song, "Triaxial strength and failure criterion of plain high-strength and high-performance concrete before and after high temperatures," Cement and Concrete Research, vol. 40, no. 4, pp. 171-178, 2010.

[27] H.-S. Shang, Y.-P. Song, and L.-K. Qin, "Experimental study on strength and deformation of plain concrete under triaxial compression after freeze-thaw cycles," Building and Environment, vol. 43, no. 7, pp. 1197-1204, 2008.

[28] Z. Yu, Q. Huang, X. Xie, and N. Xiao, "Experimental study and failure criterion analysis of plain concrete under combined compression-shear stress," Construction and Building Materials, vol. 179, pp. 198-206, 2018.

[29] N. Liang, P. Yang, X. Liu, Y. Zhong, and Z. Guo, "A study on dynamic compressive mechanical properties of multi-size polypropylene fiber concrete under high strain rate," Materials Review, vol. 32, no. 2, pp. 288-294, 2018.

[30] C. Rong, Q. Shi, T. Zhang, and H. Zhao, "New failure criterion models for concrete under multiaxial stress in compression," Construction and Building Materials, vol. 161, pp. 432-441, 2018.

[31] F. Xie, D. Cai, L. Ji, C. Zhang, R. Jing, and L. Xiao, "Combined compression-shear performance and failure criteria of internally cured concrete with super absorbent polymer," Construction and Building Materials, vol. 226, Article ID 120888, 2021.

[32] Z. Yu, Q. Huang, X. Xie, and B. Lu, "Comparative study on compressive-shear behavior of ordinary concrete and lightweight aggregate concrete," Materials Review, vol. 32, no. 24, pp. 4269-4275, 2018.

[33] M. A. Khan, S. A. Memon, F. Farooq, M. F. Javed, F. Aslam, and R. Alyousef, "Compressive strength of fly-ash-based geopolymer concrete by gene expression programming and random forest," Advances in Civil Engineering, vol. 2021, Article ID 6618407, 17 pages, 2021. 